\title{
Comparative efficacy of sign surveys, spotlighting and audio playbacks in a landscape-scale carnivore survey
}

\author{
Michelle Thorn ${ }^{1,2^{*}}$, Matthew Green ${ }^{2}$, Philip W. Bateman ${ }^{2}$, Elissa Z. Cameron ${ }^{2}$, \\ Richard W. Yarnell ${ }^{3}$ \& Dawn M. Scott ${ }^{1}$ \\ ${ }^{1}$ Biology Division, University of Brighton, Cockcroft Building, Lewes Road, Moulsecoomb, Brighton, BN2 4GJ, U.K. \\ ${ }^{2}$ Mammal Research Institute, Department of Zoology and Entomology, University of Pretoria, Pretoria, 0002 South Africa \\ ${ }^{3}$ School of Animal, Rural and Environment Sciences, Nottingham Trent University, Brackenhurst, Southwell, \\ Nottinghamshire, NG25 OQF, U.K. \\ Received 28 May 2009. Accepted 15 January 2010
}

\begin{abstract}
Many carnivores are difficult and labour-intensive to detect, often leading to prohibitively high effort and cost in large-scale surveys. However, such studies provide information that is important for effective management and conservation. Here, we evaluate the suitability of three survey methods for landscape-scale multi-species monitoring. We compare sign surveys, spotlighting, and audio playbacks in terms of detection efficiency, precision, effort, and cost. Sign surveys out-performed the other methods in all comparison criteria, although supplementary methods were needed for some species and sites. We found that using established analysis techniques, robust landscape-scale abundance estimates would require unrealistically high effort and cost. Occupancy estimation required considerably lower sample sizes and was therefore more economical. We conclude that sign-based occupancy estimates constitute a versatile and efficient option for future large-scale, multi-species carnivore surveys.
\end{abstract}

Key words: Africa, caracal, carnivore, hyaena, jackal, landscape, monitoring, survey.

\section{INTRODUCTION}

Effective management and conservation of wildlife populations requires accurate knowledge of occurrence, abundance, and the factors that influence spatial and temporal patterns in these variables (Zielinski 1997; Wilson \& Delahay 2001; Barea-Azcon et al. 2007). However, for carnivores, such information is often lacking (Nowell \& Jackson 1996; Mills \& Hofer 1998; Sillero-Zubiri et al. 2004). Finding efficient and practical ways to acquire that knowledge is of wide relevance and increasing urgency in view of globally declining carnivore populations and increasing human-carnivore conflict (Treves \& Karanth 2003; Inskip \& Zimmermann 2009). However, this is a challenging task: carnivores are often solitary, cryptic, nocturnal, or occur at low density, making them inherently difficult and labour intensive to detect (Zielinski 1997; Wilson \& Delahay 2001; Gompper et al. 2006; Barea-Azcon et al. 2007). In addition, many medium- and large-sized species range over extensive areas that encompass widely varied ecological conditions (Nowell \& Jackson 1996;

\footnotetext{
*To whom correspondence should be addressed

E-mail: thorn green@hotmail.com
}

Mills \& Hofer 1998; Sillero-Zubiri et al. 2004).

The challenges associated with surveying carnivores necessitate methods that are effective at large spatial scales and over a broad spectrum of population densities (Zielinski 1997; Barea-Azcon et al. 2007), particularly in studies addressing landscape-scale questions such as distribution or macro-habitat associations. However, attempts at large-scale carnivore surveys are often hindered by high effort and cost, logistical difficulties, and habitat-specific variations in the efficacy of sampling methods (Zielinski 1997; Gompper et al. 2006; Barea-Azcon et al. 2007). Multi-species surveys can increase the productivity of field work and offer important inter-specific insights, but they are further complicated by species-specific variations in methodological performance (Gompper et al. 2006). Consequently, there are few examples of standardized carnivore survey protocols for use across large, heterogeneous areas (Barea-Azcon et al. 2007) and still fewer for large-scale multispecies work (Gompper et al. 2006). Hence, our aim was to identify suitable methods for largescale monitoring surveys of medium- and largesized African carnivores as a preliminary step to 
designing a multi-species, landscape-scale protocol.

We used sign surveys, spotlighting, and audio playbacks because they are non-invasive techniques that have been successfully used in previous multi-species studies of African carnivores. In addition, these sampling methods can be implemented without highly technical equipment or facilities, making them widely accessible to other investigators. Sign surveys (counts of scats, tracks, feeding signs, claw marks, dens and other visible structures) have been used world-wide to study a broad spectrum of focal carnivore species (Wilson \& Delahay 2001), including cheetahs (Acinonyx jubatus), lions (Panthera leo), leopards (Panthera pardus), brown hyaenas (Hyaena brunnea) and spotted hyaenas (Crocuta crocuta) (Stander 1998; Carbone et al. 2009; Houser et al. 2009). Spotlighting along line transects has frequently been used for medium-sized species such as dingoes (Canis dingo) and red foxes (Vulpes vulpes) (Mahon et al. 1998; Edwards et al. 2000; Heydon et al. 2000) in Europe and Australia. However, the technique has also been used to inventory African mammal communities (e.g. Duckworth 1992; Monadjem et al. 1998). Audio playbacks have only been used in Africa, and only for relatively high-density populations of blackbacked jackals (Canis mesomelas, hereafter referred to as jackals), lions and spotted hyaenas (Sillero-Zubiri \& Gottelli 1992; Creel \& Creel 1996; Ogutu \& Dublin 1998; Mills et al. 2001; Ogutu et al. 2005). The efficacy of this technique has not previously been compared with that of other sampling methods.

The main objective of the study was to compare the detection efficiency and precision achieved by the methods across a range of ecological conditions and carnivore population densities. However, cost and effort were also important criteria given the limited resources available to many research and conservation projects. We also considered the relative merits of measuring occupancy and abundance as both can be used to monitor carnivore populations (Zielinski 1997; Karanth \& Nichols 2002; MacKenzie et al. 2006). Occupancy is defined as the overall proportion of a study area that is occupied by a given species (MacKenzie et al. 2002) and abundance can be measured as an index of relative values or in absolute terms (i.e. density and population size). Where possible, we measured absolute rather than relative abundance, as this measure supports a wider range of management and conservation applications (Balme et al. 2009). All of the methods selected for this study can potentially be used to measure occupancy, relative abundance and density.

\section{METHODS}

\section{Study area}

The study area of approximately $31167 \mathrm{~km}^{2}$ encompassed $24^{\circ} 95^{\prime}$ to $26^{\circ} 82^{\prime} \mathrm{S}$ and $23^{\circ} 12^{\prime}$ to $27^{\circ} 36^{\prime} \mathrm{E}$, predominantly within the North West Province of South Africa. The province receives mean annual rainfall of $200-650 \mathrm{~mm}$, with a wet season from October to March and mean daily temperatures from $32^{\circ} \mathrm{C}$ (January) to $-1^{\circ} \mathrm{C}$ (July) (De Villiers \& Mangold 2002). Seventy-one per cent is Savannah Biome, the remainder is grassland and the terrain is generally flat (De Villiers \& Mangold 2002).

The majority of the province is privately owned but approximately $10 \%$ is state-owned or tribal land. Fifty-four per cent of the province is used for grazing, $30 \%$ for crop farming, $11 \%$ for human settlement, the remainder is used for forestry, conservation and mining (Tladi et al. 2002). Although 283308 ha of the province's 11632000 ha is formally protected land it is one of the most environmentally stressed areas in South Africa (Hoffman \& Ashwell 2001).

\section{Survey sites}

We selected 25 sites to be surveyed once in the wet season and again in the dry season. This was the maximum sample size achievable within logistical and time constraints. We used stratified random sampling to identify a range of potential sites that were deemed representative of climactic conditions (high, medium and low rainfall/temperature), community composition (with and without apex predators, game and domestic livestock), and densities of carnivore species (inside and outside protected areas). We then approached landowners to request survey permission, which constrained completely random selection of sites. All surveys were completed between January 2006 and August 2007 (see Table 1 for characteristics of the sites and surveys undertaken at each).

\section{Observer skills}

D.S. and R.Y. trained all observers to operate the standardized survey protocols and all observations were rated from one (very low confidence in 
Table 1. Area, land use and survey activities completed $(\checkmark)$ at 25 sites in the North West Province of South Africa during the wet and dry seasons of 2006 and 2007.

\begin{tabular}{|c|c|c|c|c|c|c|c|c|}
\hline \multirow[b]{2}{*}{ Site } & \multirow[b]{2}{*}{ Area $\left(\mathrm{km}^{2}\right)$} & \multirow[b]{2}{*}{ Land use } & \multicolumn{2}{|c|}{ Sign surveys } & \multicolumn{2}{|c|}{ Spotlighting } & \multicolumn{2}{|c|}{ Playbacks } \\
\hline & & & Wet & Dry & Wet & Dry & Wet & Dry \\
\hline 1 & 12 & Cattle farming & $\checkmark$ & $\checkmark$ & $\checkmark$ & $\checkmark$ & $\checkmark$ & $\checkmark$ \\
\hline 2 & 22 & Cattle farming & $\checkmark$ & $\checkmark$ & $\checkmark$ & $\checkmark$ & $\checkmark$ & $\checkmark$ \\
\hline 3 & 20 & Cattle farming/agriculture & $\checkmark$ & $\checkmark$ & $\checkmark$ & $\checkmark$ & $\checkmark$ & $\checkmark$ \\
\hline 4 & 6 & Game farming & $\checkmark$ & $\checkmark$ & $\checkmark$ & $\checkmark$ & $\checkmark$ & $\checkmark$ \\
\hline 5 & 7 & Game farming & $\checkmark$ & $\mathbf{x}$ & $\checkmark$ & $\mathbf{x}$ & $\checkmark$ & $\mathbf{x}$ \\
\hline 6 & 9 & Game farming & $\checkmark$ & $\checkmark$ & $\checkmark$ & $\checkmark$ & $\checkmark$ & $\checkmark$ \\
\hline 7 & 30 & Game farming & $\checkmark$ & $\checkmark$ & $\checkmark$ & $\checkmark$ & $\checkmark$ & $\checkmark$ \\
\hline 8 & 60 & Game farming & $\checkmark$ & $\checkmark$ & $\checkmark$ & $\checkmark$ & $\checkmark$ & $\checkmark$ \\
\hline 9 & 5 & Game farming/hunting & $\checkmark$ & $\checkmark$ & $\checkmark$ & $\checkmark$ & $\checkmark$ & $\checkmark$ \\
\hline 10 & 47 & Game farming/tourism & $\checkmark$ & $\checkmark$ & $\checkmark$ & $\checkmark$ & $\checkmark$ & $\checkmark$ \\
\hline 11 & 3 & Livestock/game farming & $\checkmark$ & $\checkmark$ & $\checkmark$ & $\checkmark$ & $\checkmark$ & $\checkmark$ \\
\hline 12 & 14 & Livestock/game farming & $\checkmark$ & $\checkmark$ & $\checkmark$ & $\checkmark$ & $\checkmark$ & $\checkmark$ \\
\hline 13 & 21 & Livestock/game farming & $\checkmark$ & $\checkmark$ & $\checkmark$ & $\checkmark$ & $\checkmark$ & $\checkmark$ \\
\hline 14 & 76 & Livestock/game farming & $\checkmark$ & $\checkmark$ & $\checkmark$ & $\checkmark$ & $\checkmark$ & $\checkmark$ \\
\hline 15 & 100 & Livestock/game farming & $\checkmark$ & $\mathbf{x}$ & $\mathbf{x}$ & $\mathbf{x}$ & $\checkmark$ & $\mathbf{x}$ \\
\hline 16 & 10 & Military & $\checkmark$ & $\checkmark$ & $\checkmark$ & $\checkmark$ & $\checkmark$ & $\checkmark$ \\
\hline 17 & 120 & Mining & $\mathbf{x}$ & $\checkmark$ & $\mathbf{x}$ & $\checkmark$ & $\mathbf{x}$ & $\checkmark$ \\
\hline 18 & 25 & Protected area & $\checkmark$ & $\checkmark$ & $\checkmark$ & $\checkmark$ & $\checkmark$ & $\checkmark$ \\
\hline 19 & 35 & Protected area & $\checkmark$ & $\checkmark$ & $\checkmark$ & $\checkmark$ & $\checkmark$ & $\checkmark$ \\
\hline 20 & 43 & Protected area & $\checkmark$ & $\checkmark$ & $\checkmark$ & $\checkmark$ & $\checkmark$ & $\checkmark$ \\
\hline 21 & 130 & Protected area & $\checkmark$ & $\checkmark$ & $\checkmark$ & $\checkmark$ & $\checkmark$ & $\checkmark$ \\
\hline 22 & 235 & Protected area & $\checkmark$ & $\checkmark$ & $\checkmark$ & $\checkmark$ & $\checkmark$ & $\checkmark$ \\
\hline 23 & 240 & Protected area & $\checkmark$ & $\checkmark$ & $\checkmark$ & $\checkmark$ & $\checkmark$ & $\checkmark$ \\
\hline 24 & 550 & Protected area & $\checkmark$ & $\checkmark$ & $\checkmark$ & $\checkmark$ & $\checkmark$ & $\checkmark$ \\
\hline 25 & 750 & Protected area & $\checkmark$ & $\mathbf{x}$ & $\checkmark$ & $\mathbf{x}$ & $\mathbf{x}$ & $\mathbf{x}$ \\
\hline
\end{tabular}

species identification) to five (very high confidence). Only observations rated four or five were subsequently analysed. Each field team contained $\geq 1$ highly experienced supervisory observer, for example, M.T. and M.G. surveyed at 23 of the 25 sites.

\section{Sign surveys}

To standardize survey effort between sites of varying size, we conducted a minimum of $1 \mathrm{~km}$ of sign surveys $/ 5 \mathrm{~km}^{2}$ of site area. Again, this was the maximum effort achievable within logistical and time constraints. We conducted all surveys from a vehicle travelling at $10-15 \mathrm{~km} / \mathrm{h}$ and $\geq 2$ trained observers searched for sign (tracks and scats) on and within a $2 \mathrm{~m}$ strip either side of the road (Burgener \& Gusset 2003; Stone 2005). Sign was identified to species level based on colour, dimensions, position and presence of accompanying signs, but was not aged. Field guides (Walker 1996; Stuart \& Stuart. 2000) were consulted where necessary. We separated survey routes into $1 \mathrm{~km}$ segments and used these as spatial survey repli- cates (Kendall et al. 1992; Zielinski 1997; Barea-Azcon et al. 2007), assigning segments a binary value of ' 1 ' indicating species detection or ' 0 ' for non-detection. We used a runs test (pattern analysis) to check spatial independence of $1 \mathrm{~km}$ replicates (Kendall et al. 1992; Waite 2000) and calculated species relative abundance as the proportion of segments containing sign (Zielinski 1997; Karanth \& Nichols 2002). This eliminates potential bias in count statistics caused by repeatedly counting the same individual in a segment (Kendall et al. 1992; Zielinski 1997). We did not attempt to extrapolate relative abundance estimates to density estimates, as this requires calibration with independent estimates of species' absolute abundance in at least some of the study sites, and no such data were available.

\section{Spotlighting}

Again, we used a minimum survey effort per site of $1 \mathrm{~km} / 5 \mathrm{~km}^{2}$ and conducted all surveys between 19:00 and 00:00, completing surveys at each site on successive nights. We searched along roads 
using a 1.5 million candela spotlight, scanning both sides of the road from a vehicle travelling at $15 \mathrm{~km} / \mathrm{h}$. On detecting eye shine, observers used $8 \times 40$ binoculars to identify the animal to species level and recorded its distance along the transect and the perpendicular distance from the transect route. We analysed the results in the same way as sign survey data.

\section{Audio playbacks}

We conducted playbacks in all conditions except during rain or high winds ( $\geq 2$ on the Beaufort scale) (Ogutu \& Dublin 1998; Mills et al. 2001) and undertook all surveys between 19:00 and 00:00. We used a minimum sampling intensity of $20 \%$ of the total area of each site to ensure that reliable density estimates could be calculated (Ogutu \& Dublin 1998; Stone 2005). We separated playback locations by at least $5 \mathrm{~km}$, surveyed adjacent sites consecutively and completed surveys at each site on successive nights to minimize the risk of double counting or habituation (Ogutu \& Dublin 1998; Stone 2005). Each playback was considered a spatial replicate.

We adapted our protocol from Mills et al. (2001) but restricted our audio lure to a pig (Sus scrofa) distress call rather than a repertoire of prey and carnivore vocalizations. We played the call at $122 \mathrm{~dB}$ through two $5 \times 8,30 \mathrm{~W}$ horn speakers connected to a two-channel $200 \mathrm{~W}$ Mikkai car amplifier, placed on the roof of a vehicle. We repeated the call four times for three minutes each time, separated by a five-minute interval. After each call we rotated the speakers through $90^{\circ}$. After playing the call in all four directions, we waited 18 minutes to allow sufficient time for animals to respond. Observers searched the area with a red-filtered 1.5 million cd spotlight at approximately two-minute intervals. On detecting eye shine, observers used $8 \times 40$ binoculars to identify the animal to species level. The filter marginally reduced visibility but when it was used, responding animals came closer to the vehicle, thereby aiding species identification.

Calibration data was taken from 20 calibration experiments conducted in Pilanesberg National Park (Stone 2005) using the protocol described in Ogutu \& Dublin (1998) and Mills et al. (2001). From these experiments, the circular area surveyed during each playback was calculated as $\pi r^{2}$, where $r$ was the maximum distance at which a member of the relevant species was observed to hear the call. All individuals tested within this distance were considered to have been exposed to the calibration playbacks. Response probability was calculated as the proportion of animals from each species that responded positively, having been exposed to the call.

We then calculated density estimates following Ogutu \& Dublin (1998). The number of individuals that should be tested during calibrations to achieve unbiased density estimates at Pilanesberg was then calculated using the following equation from Mills et al. (2001), where $E(\hat{\mu})$ is the expected number of individuals within the response range, $\mu$ is the number of individuals observed during calibration experiments and $\pi$ is the response probability:

$$
E(\hat{\mu})=\mu\left(1+\frac{(1-\pi)}{\mu \pi}\right)
$$

\section{Methodological comparisons}

We estimated detection efficiency of each method at each site as the number of medium- and large-bodied carnivore species ( $\geq 10 \mathrm{~kg}$ adult body weight) detected by the individual method/ total number of carnivore species detected by all three methods. For frequently detected species, we also evaluated relative methodological efficacy based on precision, effort, and cost. We calculated precision at each site as the per cent coefficient of variation (CV) of relative abundance or density values from individual replicates. Effort was defined as the minimum sample size required to detect a $20 \%$ change in landscape-scale abundance and occupancy estimates with $80 \%$ statistical power and $\alpha=0.05$ (Zielinski 1997). Separate power analyses were conducted on the abundance estimates for all sites and on the overall proportion of sites occupied. To compare the costs of landscape-scale surveys, it was first necessary to determine the number of replicates required at each sample unit (site). We assumed this to be the mean number of replicates required to stabilize $\mathrm{CV}$ for each method, which we calculated by graphically plotting the $\mathrm{CV}$ of cumulative mean relative abundance against increasing sampling effort (Waite 2000; Scott et al. 2005).

Occupancy and detection probability estimates would be required to determine minimum effort for occupancy surveys (Royle \& Nichols 2005). As such data were unavailable, we assumed the same number of replicates for occupancy and abundance surveys. We then multiplied the cost/average-sized site (number of replicates $x$ cost per replicate) by the minimum sample size 
Table 2. Percentage of sites $(n=25)$ where carnivore species were detected, by method, and for all methods combined, together with mean abundance (proportion of segments where the species was recorded) detected by sign surveys and spotlighting, and density (individuals $/ 100 \mathrm{~km}^{2}$ ) detected by playbacks. '-'indicates that it was not possible to calculate density. Surveys were conducted in the North West Province of South Africa during 2006 and 2007.

\begin{tabular}{|c|c|c|c|c|c|c|c|}
\hline \multirow[b]{2}{*}{ Species } & \multicolumn{4}{|c|}{$\%$ of sites where species was detected } & \multicolumn{3}{|c|}{ Mean abundance detected ( \pm S.E.) } \\
\hline & Sign surveys & Spotlighting & Playback & Combined & Sign surveys & Spotlighting & Playback \\
\hline Brown hyaena & 64.0 & 12.5 & 16.0 & 64.0 & $0.16( \pm 0.04)$ & $<0.01$ & $0.01( \pm 0.01)$ \\
\hline Jackal & 84.0 & 12.5 & 60.0 & 92.0 & $0.26( \pm 0.04)$ & $<0.01$ & $0.12( \pm 0.04)$ \\
\hline Leopard & 28.0 & 0.0 & 12.0 & 32.0 & $0.03( \pm 0.01)$ & $<0.01$ & - \\
\hline Caracal & 32.0 & 12.5 & 8.0 & 40.0 & $0.03( \pm 0.01)$ & $<0.01$ & - \\
\hline Serval & 20.0 & 4.2 & 4.0 & 24.0 & $0.01( \pm 0.01)$ & $<0.01$ & - \\
\hline
\end{tabular}

indicated by power analysis. Finally, we apportioned daily vehicle costs according to the ratio of time required to survey a site using each method and added in equipment costs that did not vary with effort.

Overall cost therefore illustrates the comparative cost of an annual monitoring survey. We excluded subsistence, accommodation and inter-site travel costs because they varied in a manner unconnected to the methods or were not measured rigorously.

The software package MINITAB 14.2 (Minitab Inc.) was used for all statistical analysis. Prior to performing parametric statistical tests we used an Anderson-Darling test to check normality of the data. We then arcsine transformed non-normally distributed proportions or percentages and square root-transformed count data (Waite 2000).

\section{RESULTS}

We completed $963 \mathrm{~km}$ of sign surveys, $1493 \mathrm{~km}$ of spotlighting, and 119 audio playbacks. Runs tests on 59 sign survey routes showed a non-random pattern of sign deposition in $8.5 \%$ of routes. Results for spotlighting survey routes were similar with $12.5 \%$ of segments showing non-random sighting patterns. We therefore assumed minimal dependence between $1 \mathrm{~km}$ segments. We found no significant differences in abundance estimates for any species between seasons (ANOVA sign surveys, $F_{1,200}=0.03, P=0.860$; spotlighting, $F_{1,160}=3.60$, $P=0.060$; playbacks, $F_{1,80}=1.00, P=0.321$ ) so all records were pooled for further analysis.

The proportion of sites where species were detected (occupancy) varied considerably by method (Table 2). The same was true of abundance, which was calculated as relative abundance for sign surveys and spotlighting, and density for playbacks. Of the five carnivore species detected in multiple sites, leopards were not detected by spotlighting at any site, but the other two methods detected all five species. The highest number of spotlighting sightings for a single species in a single site was 16 brown hyaenas.

We were unable to attract approximately $8 \%$ of animals responding to audio playbacks close enough for species identification. Leopards, serval (Leptailurus serval) and caracals; (Caracal caracal) were detected during audio playbacks but not during calibration experiments, precluding calculation of density or the number of observations required for unbiased estimates. However, we were able to calculate density for brown hyaenas and jackals. Response probability from the calibration experiments was 0.375 for brown hyaenas, with a maximum response distance of $1.44 \mathrm{~km}$ and an effective sample area of $6.51 \mathrm{~km}^{2}$. Response probability for jackals was 0.2 with a maximum response distance of $2.49 \mathrm{~km}$ and an effective sample area of $19.48 \mathrm{~km}^{2}$. We found that reducing bias in density estimates to $1.02(\approx$ no bias) would require observation of 70 brown hyaenas and 165 jackals during calibrations.

Approximately $15 \%$ of sign observations could not be reliably identified to species level. Presence of all species was detected in a higher proportion of sites when both scats and prints were recorded, as opposed to the proportion calculated only from scat observations $(50 \%$ higher for brown hyaenas, $183 \%$ for jackals, $400 \%$ for leopards, and $500 \%$ for caracals). Serval scats were not observed in any sites but prints were detected in four.

Mean methodological detection efficiency varied significantly (ANOVA $F_{2,70}=45.08, P<0.001$ ). Sign surveys detected a significantly higher mean proportion of species $(0.89 \pm 0.05$ S.E. $)$ than the other methods and the difference between playbacks $(0.35 \pm 0.07$ S.E. $)$ and spotlighting $(0.12 \pm 0.05$ S.E.) was near significant. 


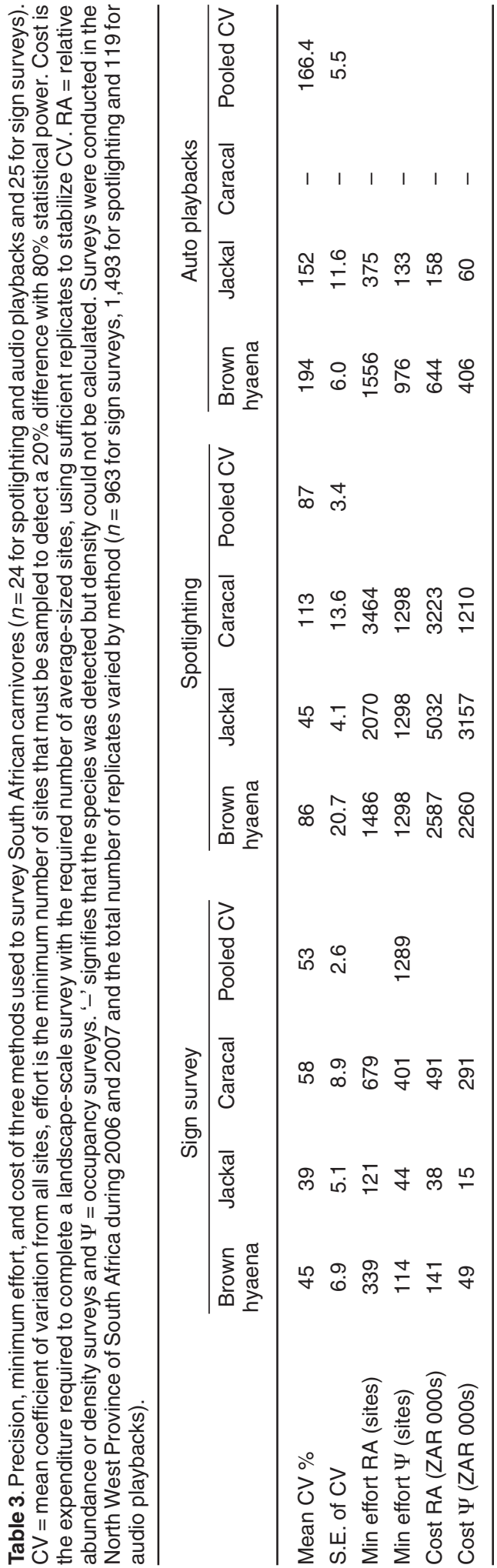

When we pooled all data by method, sign surveys were significantly more precise than spotlighting, which in turn was more precise than playbacks (ANOVA $F_{2,81}=71.03, P<0.001$; Table 3 ). Overall, sign surveys required the smallest sample sizes for measuring both abundance and occupancy of all species and occupancy surveys required a mean of $47 \%$ (range $13 \%$ to $65 \%$ ) smaller sample sizes than abundance surveys. Sign survey costs were at least an order of magnitude lower than corresponding costs for other methods (with the exception of the jackal playback result), and playbacks were less expensive than spotlighting.

Finally, we illustrated overall methodological performance by ranking the relative performance of each method for each criterion from 1 (bestperforming method) to 3 (worst-performing method; Table 4). Sign surveys performed best in all four comparisons.

\section{DISCUSSION}

Our study was the first to test these three sampling methods simultaneously and offers a useful insight into their relative efficacy for landscapescale work in Africa. In agreement with other comparative studies, we found that sign surveys detect carnivores more efficiently and at lower cost and effort than other methods (Foresman \& Pearson 1998; Silveira et al. 2003; Gompper et al. 2006; Barea-Azcon et al. 2007). However, we also found that no single technique offered optimal efficiency for all focal species and sites. Our results do not account for possible heterogeneity in detection probability, which may have biased some abundance and occupancy estimates. For this reason, we did not attempt to infer spatial, temporal, inter-specific or between-method patterns of abundance or occupancy from the data.

\section{Methodological performance}

Spotlighting was the least effective method for surveying carnivore populations at a large spatial scale. Detection efficiency was by far the lowest and as in Edwards et al. (2000), precision was lower than for sign surveys. This was partly due to limited visibility in disturbed habitat, where encroachment of fast-growing shrubs caused patches of dense vegetation. This contributed to low sighting frequencies and consequently, poor precision. Other authors have reported similar difficulties (Mahon et al. 1998; Edwards et al.2000; Heydon et al. 2000; Scott et al. 2005) and some suggest spotlighting only where visibility is good. 
Table 4. Ranking of the three sampling methods by mean efficiency with which medium and large carnivores were detected, precision (mean CV), minimum effort (number of sites required for landscape-scale surveys) and the estimated cost of annual monitoring surveys. A rank of 1 denotes the best performing method and 3 denotes the worst.

\begin{tabular}{lcccc}
\hline Method & Detection efficiency & Precision & Minimum effort & Cost \\
\hline Sign surveys & 1 & 1 & 1 & 1 \\
Spotlighting & 3 & 2 & 3 & 3 \\
Playbacks & 2 & 3 & 2 & 2 \\
\hline
\end{tabular}

This may unacceptably constrain selection of sampling sites in study areas where disturbed habitat is extensive. Moreover, poor precision and detection efficiency translated to high landscapescale effort and cost, further undermining the large-scale utility of the technique.

Playbacks achieved higher detection efficiency than spotlighting, but significantly lower than sign surveys. Precision was poor both in absolute terms, and relative to the other methods. Visibility affected the results less than spotlighting because densely vegetated patches are avoidable when choosing playbacks locations. Low sighting frequencies are therefore more likely attributable to behavioural factors. For example, playbacks are often used in lethal control of predators in nonprotected areas, which may have lead to habituation or aversion. Moreover, the audio lure may have been insufficiently attractive to satiated individuals (Mills et al.2001), or predominantly non-scavenging species like serval and caracal (Carbone et al. 2009). This may explain why scavengers such as brown hyaenas and jackals were detected more frequently than other species during playbacks. To improve multi-species detection efficiency we therefore recommend experimenting with combined food and audio lures. An audio repertoire incorporating distress calls from alternative prey species and social or agonistic carnivore vocalizations may also improve performance (Mills et al.2001).

Sign surveys were the most successful method for surveying carnivore populations at a large spatial scale. High detection efficiency produced comparatively large sample sizes and thereby, relatively high precision. Sign accumulates over time, increasing detection probability (Plumptre 2000; Wilson \& Delahay 2001; Karanth \& Nichols 2002) whereas spotlighting and playbacks sample only a fraction of the focal species' activity period at each site (Mahon et al. 1998; Edwards et al. 2000; Kiffner et al. 2007). Combined with visibility and behavioural issues, this explains why spotlighting and playbacks failed to detect species in up to $79.5 \%$ and $48 \%$ of sites, respectively, compared with $\leq 8 \%$ for sign surveys (see Table 2 ). 'False absences' were considerably reduced for all species when observations of prints as well as scats were analysed and we therefore recommend that future large-scale sign surveys incorporate both. However, it proved difficult to identify prints at sites with deep sand or rocky substrate and we were often unable to differentiate caracal and serval sign (especially scats). Other studies have also encountered such problems (Silveira et al. 2003; Gompper et al. 2006; Barea-Azcon et al. 2007). Recommended remedies include using expert trackers as in Stander (1998) or using additional methods (Foresman \& Pearson 1998; Taberlet et al. 2001; Gompper et al. 2006; Barea-Azcon et al. 2007). Neither spotlighting nor playbacks achieved sufficient detection efficiency to be considered viable solutions, but Linkie et al. (2007) found that camera trapping improves carnivore detection probability at sites where sign is difficult to find or identify. Alternatively, DNA analysis of faecal samples is an increasingly popular method that can confirm species identification from scats and provide additional data on a wide spectrum of population variables (Taberlet et al. 2001; Wilson \& Delahay 2001; Gompper et al. 2006).

\section{Abundance and occupancy}

We found that large-scale estimation of absolute abundance is likely to be impractical using established analytical techniques. Accurate spotlighting density estimates can be calculated using distance sampling methods (described in detail in Buckland et al. 1993). However, species sighting frequencies in our study fell far short of the $60-80$ observations required for precise estimates, even with spatial or temporal amalgamation of the data. Landscapescale density estimates from audio playbacks are similarly constrained by the number of individuals that must be observed during calibration (e.g. 165 jackals) and by low sighting frequencies. Sign 
surveys have been used to estimate absolute abundance of tigers (Panthera tigris), cheetahs, lions, leopards, brown hyaenas and spotted hyaenas (Stander 1998; O'Brien et al. 2003; Carbone et al. 2009; Houser et al. 2009). This requires calibration against independent estimates of density, which were unavailable in our study area. Other landscape-scale studies will likely encounter similar difficulties, given a general shortage of data on carnivores outside protected areas (Nowell \& Jackson 1996). Double sampling with a direct method (e.g. spotlighting and playbacks) can generate simultaneous and independent density estimates. However, direct methods require comparatively high effort and cost (Stander 1998) which, as our results demonstrate, are likely to be prohibitive.

Relative abundance indices (such as those calculated from our spotlighting and sign survey encounter rates) are often employed when estimating absolute abundance is impractical (Edwards et al. 2000; Karanth \& Nichols 2002). Indices can be used to address a broad spectrum of ecological questions and are frequently used to make temporal or spatial comparisons for monitoring purposes (Edwards et al. 2000; Karanth \& Nichols 2002; MacKenzie \& Kendall 2002). They can be calculated without distance sampling or playback calibration, and could therefore be used for all three methods. However, this approach is not suitable for applications requiring measurement of absolute abundance, such as setting sustainable hunting quotas (Balme et al. 2009) or determining conservation status. Furthermore, indices assume a monotonic, linear relationship between relative and absolute abundance, and spatial and temporal index comparisons are confounded unless heterogeneity in detection probability is properly accounted for (Karanth \& Nichols 2002; MacKenzie \& Kendall 2002). In practice, few carnivore studies have incorporated detection probability into index values and demonstrated a linear relationship with absolute abundance (Balme et al. 2009). This is probably because the prohibitive additional cost and effort required counteract the benefits of indices.

Like Zielinski (1997), our results suggest that landscape-scale occupancy surveys would be less expensive and require smaller sample sizes than abundance surveys. Following recent methodological advances, occupancy modelling can provide robust estimates of variables such as distribution, habitat associations, metapopulation dynamics and species interactions (MacKenzie et al. 2006). As with relative abundance indices, spatial or temporal comparisons would require estimation of detection probability in at least a subset of sites (MacKenzie et al. 2006). However, newly developed sign survey protocols achieve this without incurring additional cost and effort: detection probability is estimated directly from single surveys of multiple trail segments (Thorn 2009; Hines et al. in press). Furthermore, models for estimating absolute abundance from occupancy data are now available (Royle \& Nichols 2003; MacKenzie et al. 2006). Nevertheless, few studies have tested the suitability of the new models for mammal surveys. To the best of our knowledge, only four published studies have used occupancy modelling techniques for carnivores (see Linkie et al. 2007; Baldwin \& Bender 2008; Boulanger et al. 2008; Thorn et al. 2009), none of which used occupancy models to estimate abundance. Occupancy modelling is therefore an appealing but relatively untested option for analysing carnivore data.

\section{Implications for future studies}

We conclude that neither spotlighting nor playbacks are likely to be suitable for large-scale carnivore surveys. Spotlighting is more appropriate for intensive studies in areas with good visibility and relatively high population sizes, thereby enhancing detection efficiency. Audio playbacks are best suited to large, high-density protected areas, where carnivore persecution is unlikely and sufficient calibration experiments can be conducted without risking habituation. Occupancy based sign surveys offered the most robust, efficient and versatile foundation for a large-scale, multi-species survey. The results of this study will be used to construct and test such a protocol. However, additional studies will be required to determine the optimum allocation of effort between sign surveys and supplementary methods, and to quantify their combined efficacy. Further information is also required on the accuracy of sign surveys in relation to actual occupancy and population size, to ensure that estimates properly reflect the real properties and dynamics of focal populations.

\section{ACKNOWLEDGEMENTS}

We are indebted to the private landowners, the North West Parks and Tourism Board, and Atherstone Collaborative Nature Reserve who allowed us to survey their land, and to K. Marnewick and D. Cilliers for initial introductions to landowners. 
We thank N. Ball, E. Stone, and all of the Earthwatch volunteers who collected data. We are grateful to anonymous reviewers for valuable comments on the manuscript, and to S. Uzzell for the computer equipment he provided. Thanks to the Earthwatch Institute (via Project Phiri), Chester Zoo, U.K., the University of Brighton, U.K. and the Leverhulme Trust, U.K. for funding.

\section{REFERENCES}

BALDWIN, R.A. \& BENDER, L.C. 2008. Distribution, occupancy, and habitat correlates of American martens (Martes americana) in Rocky Mountain National Park, Colorado. J. Mammal. 89: 419-427.

BALME, G.A., HUNTER, L.T.B. \& SLOTOW, R. 2009. Evaluating methods for counting cryptic carnivores. J. Wildl. Manage. 73: 433-441.

BAREA-AZCON, J.M., VIRGOS, E., BALLESTEROSDUPERON, E., MOLEON, M. \& CHIROSA, M. 2007. Surveying carnivores at large spatial scales: a comparison of four broad-applied methods. Biodiversity Conserv. 16: 1213-1230.

BOULANGER, J., WHITE, G.C., PROCTOR, M., STENHOUSE, G., MACHUTCHON, G. \& HIMMER, S. 2008. Use of occupancy models to estimate the influence of previous live captures on DNA-based detection probabilities of grizzly bears. J. Wildl. Manage. 72: 589-595.

BUCKLAND, S.T., ANDERSON, D.R., BURNHAM, K.P. \& LAAKE, J.L. 1993. Distance sampling: estimating abundance of biological populations. Chapman and Hall, London.

BURGENER, N. \& GUSSET, M. 2003. The feeding habits of brown hyaenas (Hyaena brunnea) on a game ranch in Limpopo Province, South Africa. Afr. Zool. 38: 181-184.

CARBONE, C., MADDOX, T., FUNSTON, P.J., MILLS, M.G.L., GRETHER, G.F. \& VAN VALKENBURGH, B. 2009. Parallels between playbacks and Pleistocene tar seeps suggest sociality in an extinct sabretooth cat, Smilodon. Biol. Lett. 5(1): 81-85.

CREEL, S. \& CREEL, N.M. 1996. Limitation of African wild dogs by competition with larger carnivores. Conserv. Biol. 10: 526-538.

DE VILLIERS, B. \& MANGOLD, S. 2002. The biophysical environment. In: D. Walmsley, J. Walmsley, S. Mangold \& M. Kalule-Sabiti (Eds), North West Province state of the environment report. Directorate of Environment and Conservation Management, North West Department of Agriculture, Conservation and Environment, Mmabatho.

DUCKWORTH, J.W. 1992. Sighting frequencies of nocturnal mammals in an Ethopian Rift Valley National Park. Afr. J. Ecol. 30: 90-97.

EDWARDS, G.P., DE PREU, N.D., SHAKESHAFT, B.J. \& CREALY, I.V. 2000. An evaluation of two methods of assessing feral cat and dingo abundance in central Australia. Wildlife Res. 27: 143-149.

FORESMAN, K. \& PEARSON, D.E. 1998. Comparison of proposed survey procedures for detection of forest carnivores. J. Wildl. Manage. 62: 1217-1226.
GOMPPER, M.E., KAYS, R.W., RAY, J.C., LAPOINT, S.D., BOGAN, D.A. \& CRYAN, J.R. 2006. A comparison of noninvasive techniques to survey carnivore communities in northeastern North America. Wildlife Soc. B 34: 1142-1151.

HEYDON, M.J., REYNOLDS, J.C. \& SHORT, M.J. 2000. Variation in abundance of foxes (Vulpes vulpes) between three regions of rural Britain, in relation to landscape and other variables. J. Zool. Lond. 251: 253-264.

HINES, J.E., NICHOLS, J.D., ROYLE, J.A., MACKENZIE, D.I., GOPALASWAMY, A.M., SAMBA KUMAR, N. \& KARANTH, K.U. In press. Tigers on trails: occupancy modeling for cluster sampling. Ecol. Appl. DOI: 10.1890/09-0321

HOFFMAN, T. \& ASHWELL, A. 2001. Nature divided: Land degradation in South Africa. University of Cape Town, Cape Town.

HOUSER, A-M., SOMERS, M.J., BOAST, L.K., KLEIN, R.A. \& GOOD, K.M. 2009. Spoor density as a measure of true density of a known population of free ranging wild cheetah in Botswana. J. Zool., Lond. 278: 108-115.

INSKIP, C. \& ZIMMERMANN, A. 2009. Human-felid conflict: a review of patterns and priorities worldwide. Oryx 43: 18-34.

KARANTH, K.U. \& NICHOLS, J.D. (Eds) 2002. Monitoring tigers and their prey: a manual for researchers, managers and conservationists in tropical Asia. Centre for Wildlife Studies, Bangalore.

KENDALL, C.K., METZGAR, L.H., PATTERSON, D.A. \& STEELE, B.M. 1992. Power of sign surveys to monitor population trends. Ecol. Appl. 2: 422-430.

KIFFNER, C., WALTERT, M., MEYER, B. \& MUHLENBERG, M. 2007. Response of lions (Panthera leo LINNAEUS 1758) and spotted hyaenas (Crocuta crocuta ERXLEBEN 1777) to sound playbacks. Afr. J. Ecol. 46: 223-226.

LINKIE, M., DINATA, Y., NUGROHO, A. \& HAIDIR, I.A. 2007. Estimating occupancy of a data deficient mammalian species living in tropical rainforests: sun bears in the Kerinci Seblat region, Sumatra. Biol. Conserv. 137: 20-27.

MACKENZIE, D.I. \& KENDALL, W.L. 2002. How should detection probability be incorporated into estimates of relative abundance? Ecology 83: 2387-2393.

MACKENZIE, D.I., NICHOLS, J.D., LACHMAN, G.B., DROEGE, S., ROYLE, J.A. \& LANGTIMM, C.A. 2002. Estimating site occupancy rates when detection probabilities are less than one. Ecology 83: 22482255.

MACKENZIE, D.I., NICHOLS, J.D., ROYLE, J.A., POLLOCK, K., BAILEY, L. \& HINES. J.E. 2006. Occupancy estimation and modelling - inferring patterns and dynamics of species occurrence. Elsevier, London.

MAHON, P.S., BANKS, P.B. \& DICKMAN, C.R. 1998. Population indices for wild carnivores: a critical study in sand-dune habitat, south-western Queensland. Wildlife Res. 24: 11-22.

MILLS, M.G.L. \& HOFER, H. 1998. Hyaenas: status, survey and action plan, IUCN/SSC Hyaena Specialist Group, Gland.

MILLS, M.G.L., JURITZ, J.M. \& ZUCCHINI, W. 2001. 
Estimating the size of spotted hyaena (Crocuta crocuta) populations through playback recordings allowing for non-response. Anim. Conserv. 4: 335-343.

MONADJEM, A., MONADJEM, A. C. \& PUTNAM, J. 1998. Sighting frequencies of nocturnal mammals in Swaziland. Afr. J. Ecol. 36: 280-285.

NOWELL, K. \& JACKSON, P. (Eds) 1996. Wild cats: status survey and conservation action plan. IUCN/SSC Cat Specialist Group, IUCN, Gland and Cambridge.

O'BRIEN, T.G., KINNIARD, M.F. \& WIBISONO, H.T. 2003. Crouching tigers, hidden prey: Sumatran tiger and prey populations in a tropical forest landscape. Anim. Conserv. 6: 131-139.

OGUTU, J.O. \& DUBLIN, H.T. 1998. The response of lions and spotted hyaenas to sounds playbacks as a technique for estimating population size. Afr. J. Ecol. 36: 83-95.

OGUTU, J.O., BHOLA, N. \& REID, R. 2005. The effects of pastoralism and protection on the density and distribution of carnivores and their prey in the Mara ecosystem of Kenya. J. Zool. Lond. 265 281-293.

PLUMPTRE, A.J. 2000. Monitoring mammal populations with line transect techniques in African forests. J. Appl. Ecol. 37: 356-368.

ROYLE, J.A. \& NICHOLS, J.D. 2003. Estimating abundance from repeated presence-absence data or point counts. Ecology 84: 777-790.

SCOTT, D.M., WAITE, S., MADDOX, T., FREER, R. \& DUNSTONE, N. 2005. The validity and precision of spotlighting for surveying desert mammal communities. J. Arid Environ. 61: 589-601.

SILLERO-ZUBIRI, C. \& GOTTELLI, M.D. 1992. Population ecology of spotted hyaena in an equatorial mountain forest. Afr. J. Ecol. 30: 292-300.

SILLERO-ZUBIRI, C., HOFFMANN, M. \& MACDONALD, D.W. 2004. Canids: foxes, wolves, jackals and dogs: Status survey and conservation action plan. IUCN/SCC Canid Specialist Group. IUCN, Gland and Cambridge.

SILVEIRA, L., JACOMO, A.T.A. \& DINIZ, J.A.F. 2003. Camera trap, line transect census and track surveys: a comparative evaluation. Biol. Conserv. 114: 351355.

STANDER, P.E. 1998. Spoor counts as indices of large carnivore populations: the relationship between spoor frequency, sampling effort and true density. J. Appl. Ecol. 35: 378-385.
STONE, E.L. 2005. Estimating the abundance of brown hyaena (Hyaena brunnea) in Pilanesberg National Park and Mankwe Game Reserve, South Africa using audio-playbacks, faecal surveys and spotlight counts. Manchester Metropolitan University, Manchester.

STUART, C. \& STUART, T. 2000. A field guide to the tracks and signs of southern and East African wildlife. Struik, Cape Town.

TABERLET, P., LUIKART, G. \& GEFFEN, E. 2001. New methods for obtaining and analyzing genetic data from free-ranging carnivores. In: J.L. Gittleman, S.M. Funk, D.W. Macdonald \& R.K. Wayne (Eds), Carnivore conservation (pp. 313-334). Cambridge University Press, Cambridge.

THORN, M. 2009. Carnivores of the North West Province, South Africa: abundance occupancy and conflict with humans. University of Brighton, Brighton.

THORN, M., SCOTT, D.M., GREEN, M., BATEMAN, P.W. \& CAMERON, E.Z. 2009. Estimating brown hyaena occupancy using baited camera traps. S. Afr. J. Wildl. Res. 39: 1-10.

TLADI, B., BALOYI, T. \& MARFO, C. 2002. Chapter 6. Settlement and land use patterns. In: D. Walmsley, J. Walmsley, S. Mangold \& M. Kalule-Sabiti (Eds), North West Province State of the Environment Report. Directorate of Environment and Conservation Management. North West Department of Agriculture, Conservation and Environment, Mmabatho.

TREVES, A. \& KARANTH, K.U. 2003. Human-carnivore conflict and perspectives on carnivore management worldwide. Conserv. Biol. 17: 1491-1499.

WAITE, S. 2000. Statistical ecology in practice: a guide to analysing environmental and ecological field data. Pearson Education Limited, Harlow.

WALKER, C. 1996. Signs of the wild: A field guide to the spoor and signs of the mammals of southern Africa. Struik, Cape Town.

WILSON, G.J. \& DELAHAY, R.J. 2001. A review of methods to estimate the abundance of terrestrial carnivores using field signs and observation. Wildlife Res. 28: 151-164.

ZIELINSKI, W.J. 1997. Monitoring mesocarnivore population status. In: J. Harris \& C. Ogan (Eds), Mesocarnivores of northern California: biology, management, and survey techniques (pp. 119-127). The Wildlife Society, California North Coast Chapter, Humboldt State University, Arcata.

Corresponding Editor: J. Marshall 